side of the bed, insertion of a percutaneous endoscopic gastrostomy tube will not necessarily prevent this as these tubes may themselves be pulled out by a determined patient - indeed, some authorities believe that psychosis and dementia are relative contraindications to insertion. ${ }^{8}$

Thus percutaneous endoscopic gastrostomy is not the end of the line for nasogastric feeding but an example of one of several useful techniques that may be considered for long term enteral feeding. Nasoenteral tubes will continue to provide the main route of access for most patients requiring enteral nutrition.

JASON PAYNE-JAMES

London E97AP

1 Forgacs I, Macpherson A, Tibbs C. Percutaneous endoscopic gastrostomy. BMf 1992;304: 1395-6. (30 May.)

2 Park RHR, Allison MC, Lang J, Spence E, Morris AJ, Danesh BJZ, et al. Randomised comparison of percutaneous endoscopic B]Z,et al. Randomised comparison of percutromy and nasogastric tube feeding in patients with
gastrostome gastrostomy and nasogastric tube feeding in patients
neurological dysphagia. BMF 1992;304:1406-9. (30 May.)

Wilcock H, Armstrong J, Cottee S, Neale G, Elia M. Artificial nutrition support for patients in the Cambridge health district. Health Trends 1991;23:93-100.

4 Payne-James J, de Gara C, Grimble G, Rees R, Bray J, Rana S, $a l$. Nuritional support in hospitals in the United Kingdom: national survey 1988. Health Trends 1990;22:9-13.

5 Stiegmann GV, Goff JS, Silas D, Pearlman N, Sun J, Norton L. Endoscopic versus operative gastrostomy: final results of prospective randomised trial. Gastrointest Endosc 1990:36:1-5.

6 Payne-James JJ, de Gara CJ, Grimble GK, Bray MJ, Rana SK, Kapadia S, et al. Artificial nutrition support in hospitals in the United Kingdom. Second nutional survey United Kingdom. Second national survey. Clin Nutr in press copict scopically guided percutaneous gastrostomy and gastr-

Diksein JA, Richard W, Sharp K

8 Dikshem complications following percutaneous endoscopic gastrostom Am Surg 1989.55:82-6.

AUTHOR's REPLY, - Jason Payne-James may have read our editorial rather too closely. It is, of course, important to distinguish the functions of an editorial from those of a detailed review. The purpose of our piece, to which Payne-James takes such exception, was to introduce percutaneous endoscopic gastrostomy and not to review the whole topic of enteral nutrition in hospital practice.

As our article was written to accompany the study by Park and colleagues it seems curious that it could be interpreted as recommending that endoscopic gastrostomy feeding should replace nasogastric feeding for short term nutritional support over just a few days. Even the most ardent gastrostomist might baulk at such a suggestion.

It is correct to suggest that the main hazards of operative gastrostomy are related to the anaesthetic. But it has always seemed a little unfair to blame the anaesthetist for a postoperative death when he or she was called into action only because a surgeon decided to perform an operation. Despite PayneJames's comments we continue to recommend endoscopic rather than operative gastrostomy for most of our patients.

A comprehensive review of enteral nutrition would surely have emphasised the radiologist's potential in siting gastrostomy tubes. Many endoscopists faced with ever increasing workloads would welcome the help of colleagues from the $x$ ray department in lightening their burden.

The image of a patient with hands bandaged to the sides of the bed was intended to be emotive but does illustrate the point about the continuing discomfort that patients can experience with nasogastric tubes. Our clinical experience of nutrition in hospital practice, like that of the patients in Park and colleagues' study, is that a gastrostomy tube is not only more successful but is better tolerated over the long term than a nasogastric tube. As with any treatment, the patient's mental state must be taken into consideration when the route for nutritional support is being planned.

\section{Psychosocial problems in epilepsy}

EDITOR,-J E Chaplin and colleagues' paper provides interesting evidence on the psychosocial problems of people in whom epilepsy is newly diagnosed.' Similar evidence of good adjustment is available for another group of people with epilepsy -those in whom it is in remission-from the Medical Research Council's antiepileptic drug withdrawal study. ${ }^{2}$ As part of this study, information was collected from over 600 patients about employment, social relationships, leisure activities, feelings of stigma, and general wellbeing. The study was a randomised clinical trial, and the patients in it were a selected group, but comparison of their clinical and demographic characteristics, as well as their responses to the psychosocial questionnaire, with those of patients who were not randomised indicated that the results can be generalised to less selected populations.

Overall, in this group of patients levels of distress over epilepsy seemed to be low. ${ }^{3}$ Respondents emerged as being well adjusted to their epilepsy and experiencing few problems because of it. Rates of employment were comparable with those in the general population, and few patients reported any instances of discrimination at work attributable to epilepsy. Although the rate of marriage and cohabitation was lower than in the general population, it was higher than that reported for people with chronic epilepsy, and the proportion of people living alone did not differ from that in the population as a whole. Few patients reported any restrictions in their social life because of their epilepsy, and few reported feeling stigmatised because of it. Like Chaplin and colleagues, however, the Medical Research Council's study found that the extent of reported problems was related to the recency of the last seizure.

Similar findings of good adjustment have been reported by Trostle et al, who also found little evidence of psychosocial impairment among the population they studied. ${ }^{+}$These findings of good adjustment are important and contrast greatly with the view of epilepsy as universally stigmatising. The process of adjusting to epilepsy is one about which we know relatively little, and further research is needed. We await with interest the results of the five year follow up of the patients in the national general practice study.

ANN JACOBY

Centre for Health Services Research,

University of Newcastle upon Tyne,

Newcastle NE2 4AA

Department of Neurosciences,

DAVID CHADWICK

Walton Hospital,

Walton Hospital,

1 Chaplin JE, Lasso RY, Shorvon SD, Floyd M. National general practice study of epilepsy: the social and psychological effects (30 May.)

2 MRC Antiepileptic Drug Withdrawal Group. A randomised study of anticpileptic drug withdrawal in patients in remission study of antiepileptic drug withdrawal in

3 Jacoby A. Epilepsy and the quality of everyday life. Findings acoby A. Epilepsy and the quality of everyday life. Findings
from a study of people with well-controlled epilepsy. Soc Sci Med 1992;43:657-66.

4 Trostle JA, Hauser WA, Sharbrough FW. Psychologic and social adjustment to epilepsy in Rochester, Minnesota. Neurology 1989;39:633-7.

\section{Treating obesity in children}

EDITOR, - We are concerned about the treatment of obesity in children. A patient of ours, a 13 year old girl, was referred by her general practitioner for assessment of right sided abdominal pain. In the referral letter the general practitioner stated that she was not taking any medication. She was admitted for observation, and the pain settled spontaneously.
On close questioning for clerking on admission she admitted that she took tablets because her "metabolism was slow," resulting in her being overweight. Her mother told us that she had always been fat as a baby, and had first been treated for obesity at the age of 4 . She was currently being treated at a private slimming clinic and had been prescribed a 12 month course of "thyroid tablets," but she did not know the dosage. Her father brought the drugs in: thyroxine sodium $100 \mu \mathrm{g}$ daily, phentermine $15 \mathrm{mg}$ daily, and "Armour thyroid" two tablets daily. On repeat questioning the patient did not have any thyroid, cardiac, gastrointestinal, or menstrual irregularities. She had not had any blood tests at the private clinic. Her height was on the 10th centile for her age and her weight just below the 50th centile.

Thyroxine sodium is licensed for use in hypothyroidism.' Phentermine is structurally and pharmacologically related to the amphetamines. It is "an anorectic agent intended for short term use as an adjunct to the treatment of patients with moderate to severe obesity for whom close support and supervision are also to be provided."' It is not recommended for use in children. We could find no reference to using these drugs to treat obesity in children.

In addition to the obvious dangers of these drugs being prescribed to such a patient it is of concern that the general practitioner was not informed that his patient was being prescribed these drugs and that neither the patient nor her mother knew the exact nature or dosage of the drugs. The matter is being taken further by one of the consultant paediatricians, and we hope that such practices may be stamped out.

C A ERIKSEN B A R UJAM

Department of Surgery,

Mayday University Hospital

Thornton Heath,

Surrey CR4 7YE

1 Walker G, ed. ABPI data sheet compendium 1991-2. London: Datapharm, 1991.

\section{Coronary vasospasm and sumatriptan}

EDITOR,-F Willett and colleagues describe an episode of coronary vasospasm after subcutaneous administration of sumatriptan. ${ }^{\prime}$ The details of this case are well known to Glaxo.

The patient under discussion had complained of intermittent retrosternal chest pain for 11 months before admission in December 1991, not only in relation to methysergide and sumatriptan but also on waking. In August 1991 atypical chest pain was noted. As a consequence of the challenge with sumatriptan that the authors describe the chest pain was confirmed as Prinzmetal's angina, a point omitted in the published drug point. It is clear in retrospect, however, that the underlying problem predated treatment with sumatriptan by several months.

Although chest symptoms have been noted with sumatriptan, extensive clinical investigations have not shown ischaemic electrocardiographic changes in otherwise healthy patients after subcutaneous or oral administration. Postmarketing experience has likewise failed to show any evidence of myocardial ischaemia in the absence of symptomatic cardiac disease. Furthermore, although Willett and colleagues refer to a second report of coronary vasospasm, that report was of a patient with a history of angina and heavy smoking who was treated on several occasions with sumatriptan without chest pain but experienced a myocardial infarction two weeks after the last dose. A causal relation is therefore considered to be unlikely.

Underlying ischaemic heart disease and Prinz- 